\title{
Inhaled corticosteroid use in patients with chronic obstructive pulmonary disease and the risk of pneumonia: a retrospective claims data analysis
}

\author{
This article was published in the following Dove Press journal: \\ International Journal of COPD \\ 26 June 2013 \\ Number of times this article has been viewed
}

\author{
Barbara PYawn' \\ Yunfeng $\mathrm{Li}^{2}$ \\ Haijun Tian ${ }^{2}$ \\ Jie Zhang ${ }^{2}$ \\ Steve Arcona ${ }^{2}$ \\ Kristijan H Kahler ${ }^{2}$ \\ 'Department of Research, Olmsted \\ Medical Center, Rochester, MN, USA; \\ ${ }^{2}$ Department of Health Economics \\ and Outcomes Research, Novartis \\ Pharmaceuticals Corporation, \\ East Hanover, NJ, USA
}

\begin{abstract}
Background: The use of inhaled corticosteroids in patients with chronic obstructive pulmonary disease (COPD) has been associated with an increased risk of pneumonia in controlled clinical trials and case-control analyses.

Objective: Using claims databases as a research model of real-world diagnosis and treatment, to determine if the use and dose of inhaled corticosteroids (ICS) among patients with newly diagnosed COPD are associated with increased risk of pneumonia.
\end{abstract}

Patients and methods: This was a retrospective cohort analysis of patients diagnosed with COPD between January 01, 2006 and September 30, 2010, drawn from databases (years 2006-2010). Patients (aged $\geq 45$ years) were followed until first pneumonia diagnosis, end of benefit enrollment, or December 31, 2010, whichever was earliest. A Cox proportional hazard model was used to assess the association of ICS use and risk of pneumonia, controlling for baseline characteristics. Daily ICS use was classified into low, medium, and high doses (1 $\mu \mathrm{g}-499 \mu \mathrm{g}, 500 \mu \mathrm{g}-999 \mu \mathrm{g}$, and $\geq 1000 \mu \mathrm{g}$ fluticasone equivalents daily) and was modeled as a time-dependent variable.

Results: Among 135,445 qualifying patients with a total of 243,097 person-years, there were 1020 pneumonia incidences out of 5677 person-years on ICS (crude incidence rate, 0.180 per person-year), and 27,730 pneumonia incidences out of 237,420 person-years not on ICS (crude incidence rate, 0.117 per person-year). ICS use was associated with a dose-related increase in risk of pneumonia, with adjusted hazard ratios (versus no use; (95\% confidence interval) of 1.38 (1.27-1.49) for low-dose users, 1.69 (1.52-1.88) for medium-dose users, and 2.57 (1.98-3.33) for high-dose users $(P<0.01$ versus no use and between doses).

Conclusion: The use of ICS in newly diagnosed patients with COPD is potentially associated with a dose-related increase in the risk of pneumonia.

Keywords: COPD, ICS, LABA, pneumonia

\section{Background}

Inhaled corticosteroids (ICS) are commonly prescribed to patients with chronic obstructive pulmonary disease (COPD), with reported usage ranging from 39\%-50\% of patients in the USA, ${ }^{1} 67 \%$ in Canada, ${ }^{2}$ and $35 \%-75 \%$ of patients in various European countries. $^{3-6}$ Current COPD management strategy recommends ICS treatment in patients classed as being at high risk, defined by a history of frequent exacerbations $(\geq 2 /$ year) and/or severe airflow limitation (forced expiratory volume in 1 second $<50 \%$ predicted; Global initiative for chronic Obstructive Lung Disease [GOLD]
Correspondence: Barbara Yawn Department of Research, Olmsted Medical Center, 210 Ninth Street SE, Rochester, MN 55904, USA

Tel +l 5072872758

Fax +l 5072872722

Email byawn@olmmed.org 
stages C and D). ${ }^{7}$ The use of ICS in COPD is associated with a number of side effects, ${ }^{8}$ and the risk of these side effects may be increased by patient factors that are common in COPD, such as increasing age and multiple comorbid conditions. ${ }^{9}$ Arguably, the most serious side effect is the increased incidence of pneumonia, which has been observed among patients with COPD both in controlled clinical trials ${ }^{10-12}$ and in case-control studies, ${ }^{13}$ with an excess risk that was more pronounced with high ICS doses $(\geq 1000 \mu \mathrm{g}$ /day fluticasone equivalents). ${ }^{13}$

The increased risk of pneumonia with ICS-containing treatments for COPD is acknowledged in current management strategy and guidelines, although to varying extent, and none provide guidance on how this increased risk should inform decision making by physicians. ${ }^{7,14,15}$ There is therefore a need to increase the evidence base upon which future strategy is based. We conducted a retrospective cohort analysis with the aim of determining if the use of ICS is associated with an increased risk of pneumonia in patients with newly diagnosed COPD. This question was addressed by examining the medical and prescription drug claims of patients enrolled in either employer-sponsored health plans or having employer-paid Medicare supplemental insurance, and identifying patients with newly diagnosed COPD. The use of large claims databases such as this provides a pragmatic research model of real-world physician diagnosis and treatment that can usefully further explore potential safety concerns such as this. ${ }^{16}$ To our knowledge, this is the first study of this type to be conducted using health care resource utilization data in a nonveteran US population to investigate the incidence and risk of pneumonia among patients with newly diagnosed COPD. Patients with a new diagnosis of COPD (and without a previous asthma diagnosis) are likely to have a low level of previous corticosteroid use that could contribute to increased risk of any steroid-associated side effects. The cumulative corticosteroid dose is rarely taken into account in studies assessing pneumonia risk, ${ }^{13,17}$ though it has been shown that the risk of fractures and other adverse effects such as bruising, muscle weakness, oral candidiasis, and cataracts is strongly related to the total cumulative dose of the corticosteroid taken. ${ }^{18}$

\section{Methods Study design}

This was a retrospective cohort analysis of patients newly diagnosed with COPD between January 01, 2006 and September 30, 2010. The date of first COPD diagnosis was the date of entry of a patient into the cohort. Only newly diagnosed patients with COPD, defined as no COPD diagnosis in the previous 12 months prior to the index date, were included in the study. The 12 months prior to the COPD diagnosis date was the baseline period. Patients were followed until the earliest date of any of the following events: first pneumonia diagnosis, end of medical and pharmacy benefit enrollment, or December 31, 2010. After this, patients were treated as censored.

The study protocol was submitted to the Institutional Review Board at Olmsted Medical Center and exempted from the requirement for approval since it is a review of secondary data with no identifiable patients.

\section{Data source}

Two MarketScan ${ }^{\circledR}$ databases (Arlington, VA, USA) were used: Commercial Claims and Encounters (CCE) and CMS Supplemental and Coordination of Benefits (COB), covering the years 2005-2010. These databases capture personspecific clinical utilization, expenditures, and enrollment across inpatient, outpatient, prescription drug, and carve-out services (specialist care contracted out from within the plan) from approximately 40 million patients per year from a selection of large employers, health plans, and government and public organizations.

The CCE includes data on active employees, early retirees, those receiving continuation coverage under the Consolidated Omnibus Budget Reconciliation Act, and their dependents insured by employer-sponsored plans. The COB contains information on Medicare-eligible retirees with employer-sponsored Medicare Supplemental plans. Both the employer-paid and Medicare-paid components of care are provided.

\section{Patients}

Patients were included if they had a diagnosis of COPD (International Classification of Disease [ICD]-9 codes for chronic bronchitis [491.x], emphysema [492.x], or chronic airway obstruction [496]) between January 01, 2006 and September 30, 2010. Patients with COPD were identified on the basis of COPD-related admissions or emergency room visits or at least two COPD-related office visits on different dates. Patients were required to have continuous enrollment data for 12 months preceding the COPD diagnosis date and at least 2 months after this date. Patients were excluded if they were aged $<45$ years on the COPD diagnosis date, or if they had a history of pneumonia or ICS use in the 12-month baseline period. Patients with diagnoses of asthma, cystic fibrosis, or lung cancer, either in the baseline period or in 
the follow up period, were also excluded from the analysis. Patients using oral corticosteroids during the baseline or follow up were excluded in order to reduce any potential contribution to the incidence of pneumonia. The claims data did not provide any lung function or other outcome measures data, which may be available in the clinical trial database.

\section{Outcomes}

The primary outcome measure was the first occurrence of pneumonia among the cohort of patients with newly diagnosed COPD, implying that ICS prescription always occurred during or prior to pneumonia onset. Pneumonia events included all diagnoses (ICD-9 codes 480.x to 486.x, and 487.0), derived from outpatient, emergency department, or inpatient records. In cases where a bronchitis diagnosis was observed within 30 days prior to first pneumonia diagnosis, the bronchitis date was coded as onset of pneumonia, with the assumption that the bronchitis diagnosis was likely to be the same episode of illness. In addition, all-cause health care costs were calculated for the 30 -day periods before and after the first pneumonia diagnosis.

\section{ICS exposure and dose}

ICS exposure was defined as a prescription drug claim for inhaled beclometasone, budesonide (monotherapy and fixed dose combination with formoterol), triamcinolone, fluticasone (monotherapy and fixed dose combination with salmeterol), mometasone, and flunisolide. Daily ICS dose for each patient was converted to fluticasone equivalents with the following method: (1) quantity (number of actuations) of each filled prescription of inhaled steroid was pulled out for each patient; (2) daily dose was calculated as total number of quantity $\mathrm{x}$ strength of steroids in each product/total number of days of supply; (3) daily dose was classified into low, moderate and high dosage with reference to fluticasone equivalents (low dose, $<500 \mu \mathrm{g} /$ day fluticasone equivalents; moderate dose, $500 \mu \mathrm{g} /$ day to $<1000 \mu \mathrm{g} /$ day fluticasone equivalents; high dose, $\geq 1000 \mu \mathrm{g} /$ day fluticasone equivalents) $\cdot{ }^{19}$ In a small number of cases, a higher daily dose was used, ie, in patients who were taking two inhaled steroids at different daily doses due to a new fill prior to the previous fill being used up.

\section{Statistical methods}

Baseline demographic and clinical characteristics were described for the entire study sample, and were compared between patients with and without pneumonia (Chi-square test for categorical variables and $t$-test for continuous variables). The crude incidence rate of pneumonia was calculated as number of pneumonia incidences divided by total person-years of exposure, and it was reported by ICS use or not, and by ICS dose level. The Kaplan-Meier curve analyses were conducted to illustrate the pneumonia-free survival curves by ICS dosage level. One month all-cause health care costs before and after pneumonia were calculated and described descriptively.

The Cox proportional hazards model was used to compare the risk of pneumonia among low-dose, medium-dose, and high-dose ICS use compared with no ICS use. The ICS use was modeled as a time-dependent variable, and a patient could contribute to different levels of ICS use or no use depending on his/her daily exposure to ICS use. Models were adjusted for baseline characteristics, including age, sex, region, insurance type, COPD diagnosis year, utilization of COPD medications, comorbidity, hospitalizations, and emergency room visits (see Results for complete listing). These explanatory variables in the Cox proportional hazards model were chosen on the basis of clinical relevance prior to analysis and availability in the claims data. A sensitivity analysis was performed by including patients using oral corticosteroids at baseline or follow up period.

\section{Results}

The original total of 1,669,546 patients with newly diagnosed COPD, following exclusions, yielded a study sample of 135,445 patients who were included in the follow up analysis (Figure 1). A total of 28,750 patients (21.2\% of study sample) had pneumonia in the follow up period. Baseline demographic and clinical characteristics of the entire study sample, patients with pneumonia, and patients with no pneumonia are shown in Table 1. In general, patients with pneumonia were older, used more medications, had more comorbidities, and reported greater health care utilization at baseline.

Among 135,445 qualifying patients with a total of 243,097 person-years, there were 1020 pneumonia incidences out of 5677 person-years on ICS with a crude incidence rate of 0.180 per person-year; there were 27,730 pneumonia incidences out of 237,420 person-years not on ICS with a crude incidence rate of 0.117 per person-year (Table 2). In addition, the crude incidence rate of pneumonia increased with increasing daily ICS dose ( 0.150 for low dose, 0.247 for moderate dose, and 0.319 for high dose). This is consistent with the estimated pneumonia-free survival curves illustrated in Figure 2.

Adjusted hazard ratios (HR) from multivariate Cox proportional hazards regression (Figure 3 ) showed a statistically significant increase in risk for each dose level compared 


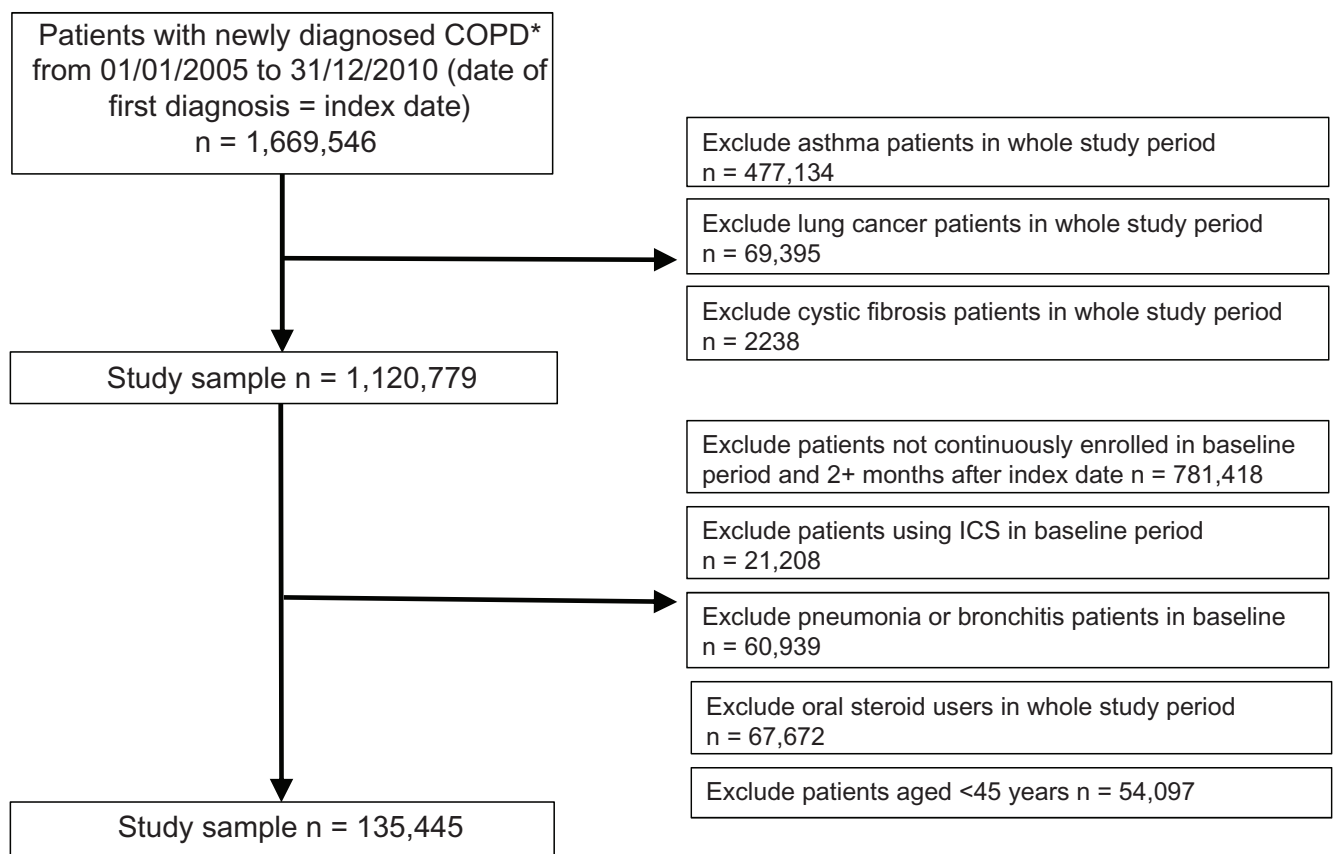

Figure I Patient selection.

Note: *COPD diagnosis was not made during the 12-month baseline period.

Abbreviations: COPD, chronic obstructive pulmonary disease; ICS, inhaled corticosteroid.

with no ICS use (low dose: $\mathrm{HR}=1.38,95 \%$ confidence interval [CI] [1.27-1.49]; median dose: $\mathrm{HR}=1.69,95 \%$ CI [1.52-1.88]; high dose: $\mathrm{HR}=2.57,95 \%$ CI [1.98-3.33]; $P<0.001$ for all), and for each stepwise increase in ICS dose level (eg, moderate versus low; high versus moderate; $P<0.01$ ). A separate Cox proportional hazards regression showed that ICS use (regardless of dose level) was associated with higher risk of pneumonia (HR $=1.51 ; 95 \% \mathrm{CI}$, 1.42-1.61; $P<0.001$ ), controlling for the same baseline covariates. The estimated HRs for covariates included in the Cox regression model are included in Supplementary Table S1. It is worth noting that previous emergency room visits, hospitalizations, congestive heart failure, drug or alcohol abuse, short-acting $\beta_{2}$-agonists, anticholinergics, and systemic glucocorticoids were significantly associated with the increased risk of pneumonia (HR $>1.1$ and $P<0.05)$. In the sensitivity analysis, where the use of oral corticosteroids was controlled in the Cox regression model, a similar magnitude and order of risk were found, with HRs of 1.58 (95\% CI, 1.49-1.68), 2.01 (95\% CI, 1.86-2.17) and 2.90 (2.42-3.46) associated with use of low-, medium-, and high-dose ICS, respectively (data not shown).

Pneumonia-related admissions were recorded for 5153 patients (18\% of pneumonia diagnoses); 200 patients ( $4 \%$ of first pneumonia admissions) were readmitted for any cause within 30 days of the first admission. All-cause health care costs in the 30 days preceding the onset of pneumonia were lower than costs in the 30 days following pneumonia onset, at US\$4017 (standard deviation [SD] \$14,715) and $\$ 6985$ (SD \$17,358) respectively, an average increase of US\$2969 (SD \$9768).

\section{Discussion}

Our results show a statistically significant and potentially dose-related increase in the risk of pneumonia associated with the use of ICS in patients with newly diagnosed COPD. An increased incidence of pneumonia in patients with COPD receiving ICS-containing treatment regimens has also been observed in controlled clinical studies, which reported an approximate doubling in incidence with ICS use compared with placebo or treatment with long-acting bronchodilators alone. ${ }^{10-12}$ The use of large administrative databases such as ours has been recommended as a pragmatic and useful method of research to further address such concerns. ${ }^{16}$

Previous observational and case-control studies either in US or Canadian populations have evaluated hospitalizations for pneumonia in veteran patients with newly diagnosed or preexisting COPD and found increased risk associated with ICS use. ${ }^{13,20}$ We can now extend these findings of increased risk associated with ICS use to apply to all recorded cases of pneumonia (ie, leading to hospitalization or not) in a nonveteran US population of patients with 
Table I Baseline demographic and clinical characteristics ${ }^{\mathrm{a}, \mathrm{b}}$

\begin{tabular}{|c|c|c|c|c|c|c|}
\hline & \multicolumn{2}{|c|}{ Total patients } & \multicolumn{2}{|c|}{$\begin{array}{l}\text { Patients with } \\
\text { pneumonia }\end{array}$} & \multicolumn{2}{|c|}{$\begin{array}{l}\text { Patients without } \\
\text { pneumonia }\end{array}$} \\
\hline & $\mathbf{n}$ & $\%$ & $\mathbf{n}$ & $\%$ & $\mathbf{n}$ & $\%$ \\
\hline Sample size & 135,445 & & 28,750 & & 106,695 & \\
\hline \multicolumn{7}{|l|}{ Follow up period (days) ${ }^{c}$} \\
\hline Mean (SD) & $669(502)$ & & $311(377)$ & & $765(487)$ & \\
\hline Median (min-max) & $573(2-1826)$ & & $153(2-1815)$ & & $675(6 \mathrm{I}-1826)$ & \\
\hline \multicolumn{7}{|l|}{ Year of COPD diagnosis } \\
\hline 2006 & $35,|3|$ & 25.9 & 9,323 & 32.4 & 25,808 & 24.2 \\
\hline 2007 & 33,332 & 24.6 & 7,824 & 27.2 & 25,508 & 23.9 \\
\hline 2008 & 28,017 & 20.7 & 5,632 & 19.6 & 22,385 & 21.0 \\
\hline 2009 & 24,166 & 17.8 & 3,950 & 13.7 & 20,216 & 18.9 \\
\hline 2010 & 14,799 & 10.9 & 2,021 & 7.0 & 12,778 & 12.0 \\
\hline \multicolumn{7}{|l|}{ Age } \\
\hline Mean (SD) & $66.99(12.66)$ & & $72.17(12.70)$ & & $65.60(12.28)$ & \\
\hline Median (min-max) & $65(45-111)$ & & $74(45-111)$ & & $63(45-104)$ & \\
\hline \multicolumn{7}{|l|}{ Sex } \\
\hline Male & 70,274 & 51.9 & 14,967 & 52.1 & 55,307 & 51.8 \\
\hline \multicolumn{7}{|l|}{ Region } \\
\hline North East & 14,540 & 10.7 & 2,894 & 10.1 & 11,646 & 10.9 \\
\hline North Central & 48,361 & 35.7 & 11,382 & 39.6 & 36,979 & 34.7 \\
\hline South & 50,022 & 36.9 & 9,962 & 34.7 & 40,060 & 37.5 \\
\hline West & 22,188 & 16.4 & 4,449 & 15.5 & 17,739 & 16.6 \\
\hline Missing & 334 & 0.2 & 63 & 0.2 & 271 & 0.3 \\
\hline \multicolumn{7}{|l|}{ Insurance type } \\
\hline Fee for service & 120,319 & 88.8 & 26,321 & 91.6 & 93,998 & 88.1 \\
\hline Non fee or service & 15,126 & 11.2 & 2,429 & 8.4 & 12,697 & 11.9 \\
\hline \multicolumn{7}{|l|}{ Drug use } \\
\hline Short-acting $\beta_{2}$-agonists & 8,107 & 6.0 & $\mathrm{I}, 98 \mathrm{I}$ & 6.9 & 6,126 & 5.7 \\
\hline Long-acting $\beta_{2}$-agonists & 401 & 0.3 & 108 & 0.4 & 293 & 0.3 \\
\hline Short-acting anticholinergics & $\mathrm{I}, 420$ & 1.0 & 461 & 1.6 & 959 & 0.9 \\
\hline Long-acting anticholinergics & 2,717 & 2.0 & 542 & 1.9 & 2,175 & 2.0 \\
\hline Methylxanthines & 3,332 & 2.5 & 923 & 3.2 & 2,409 & 2.3 \\
\hline Systemic glucocorticoids & 396 & 0.3 & 106 & 0.4 & 290 & 0.3 \\
\hline Mast-cell stabilizers & 35 & 0.0 & 7 & 0.0 & 28 & 0.0 \\
\hline Leukotriene modifiers & 2,159 & 1.6 & 467 & 1.6 & 1,692 & 1.6 \\
\hline Antibiotics & 65,470 & 48.3 & 14,948 & 52.0 & 50,522 & 47.4 \\
\hline \multicolumn{7}{|l|}{ Charlson comorbidity score } \\
\hline Mean (STD) & $1.02(1.62)$ & & $1.40(1.85)$ & & $0.92(1.53)$ & \\
\hline Median (min-max) & $0(0-2 I)$ & & I (0-I8) & & $0(0-2 I)$ & \\
\hline \multicolumn{7}{|l|}{ Comorbidity } \\
\hline Diabetes & 27,691 & 20.4 & 7,186 & 25.0 & 20,505 & 19.2 \\
\hline Pulmonary circulation disorders & 2,550 & 1.9 & 679 & 2.4 & |87| & 1.8 \\
\hline Hypertension & 56,729 & 41.9 & 13,035 & 45.3 & 43,694 & 41.0 \\
\hline Chronic pulmonary disease & 192 & 0.1 & 40 & 0.1 & 152 & 0.1 \\
\hline Alcohol abuse & 1,198 & 0.9 & 291 & 1.0 & 907 & 0.9 \\
\hline Drug abuse & 567 & 0.4 & 152 & 0.5 & 415 & 0.4 \\
\hline Congestive heart failure & 12,820 & 9.5 & 4,543 & 15.8 & 8,277 & 7.8 \\
\hline Valvular disease & 12,055 & 8.9 & 3,364 & 11.7 & 8,691 & 8.1 \\
\hline Peripheral vascular disease & 13,515 & 10.0 & 3,969 & 13.8 & 9,546 & 8.9 \\
\hline Chronic peptic ulcer & 147 & 0.1 & 43 & 0.1 & 104 & 0.1 \\
\hline Liver disease & 2,056 & 1.5 & 455 & 1.6 & 1,601 & 1.5 \\
\hline \multicolumn{7}{|l|}{ Health care resource utilization } \\
\hline All-cause hospitalization & 28,221 & 20.8 & 8,714 & 30.3 & 19,507 & 18.3 \\
\hline All-cause ED visit & 41,584 & 30.7 & 11,669 & 40.6 & 29,915 & 28.0 \\
\hline
\end{tabular}

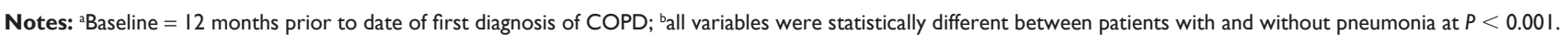
Chi-square test for categorical variables and - test for continuous variables; 'for pneumonia onset patients, follow up is from the date of COPD diagnosis to date of onset of pneumonia. For nonpneumonia onset patients, follow up is from the date of COPD diagnosis to end of enrollment or December 3 I, 2010.

Abbreviations: COPD, chronic obstructive pulmonary disease; ED, emergency department; SD, standard deviation; STD, sexually transmitted disease. 
Table 2 Crude incidence rate of pneumonia by ICS and dosage level ${ }^{\mathrm{a}}$

\begin{tabular}{lllll}
\hline ICS dose level & $\begin{array}{l}\text { Person } \\
\text { years }\end{array}$ & $\begin{array}{l}\text { Number } \\
\text { of pneumonia } \\
\text { incidences }\end{array}$ & $\begin{array}{l}\text { Incidence rate } \\
\text { of pneumonia } \\
\text { (per person year) }\end{array}$ & $\begin{array}{l}\text { Increase in incidence } \\
\text { of pneumonia compared } \\
\text { with no ICS use }\end{array}$ \\
\hline No ICS use & 237,420 & 27,730 & 0.117 & - \\
Any ICS use & 5677 & 1020 & 0.180 & $54 \%$ \\
Low-dose ICS use & 4131 & 619 & 0.150 & $28 \%$ \\
Moderate-dose ICS use & 1395 & 344 & 0.247 & $11 \%$ \\
High-dose ICS use & 151 & 57 & 0.379 & $224 \%$ \\
\hline
\end{tabular}

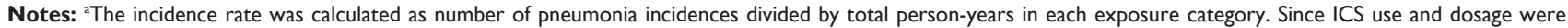
defined on a daily basis, one patient may contribute to different levels of ICS use or no use depending on his/her daily exposure to ICS use and dosage level.

Abbreviation: ICS, inhaled corticosteroid.

newly diagnosed COPD. The use of incident as opposed to prevalent cases of COPD is likely to provide a "cleaner" sample in terms of history of disease and previous treatment, in particular lessening the potential influence of cumulative corticosteroid dose (inhaled plus systemic) on the susceptibility to ICS-associated side effects. Many studies investigating the link between ICS use and pneumonia lack information on prior drug use, at least beyond baseline or the past year. ${ }^{13,17}$ While details of the severity of disease were not available to us, the use of a COPD-incident population may also have provided a more consistent population in terms of severity of disease than a more heterogeneous prevalence population, since newly diagnosed patients largely tend to be at the mild to moderate end of the spectrum of airflow limitation. ${ }^{21}$ The present population also reflects the real-life situation with respect to physician diagnosis and treatment of patients with COPD in the US. In a survey of 2187 subjects who had been told by a health professional that they had COPD, over $20 \%$ reported never having had a diagnostic breathing test. ${ }^{22}$
Compared with no ICS use, we found that the crude incidence of pneumonia was $28 \%$ higher in the low-dose ICS group, $111 \%$ higher in the moderate-dose group, and 224\% higher in the high-dose ICS group. Multivariate Cox regression also showed dose-related increases in risk of pneumonia with adjusted HRs of 1.38, 1.69, and 2.57 for low-, moderate-, and high-ICS dose versus no ICS use. In addition, there was approximately a US\$3000 increase in health care cost during the 30 days following pneumonia onset.

Long-acting bronchodilators, either long-acting anticholinergics or long-acting $\beta_{2}$-agonists (LABAs), form a major part of current treatment strategy for COPD, either alone or (for patients at higher risk) in combination with ICS. ${ }^{7}$ A 2011 Cochrane systematic review compared ICS and LABA treatment in COPD with the incidence of pneumonia as a coprimary outcome. ${ }^{23}$ It found a significantly higher incidence of pneumonia among patients on ICS compared with those receiving LABAs, with odds ratios (ICS versus LABA) of 1.38 (95\% CI, 1.10-1.73) for pneumonia as an adverse event and 1.48 (95\% CI, 1.13-1.93) for a serious adverse event. Another

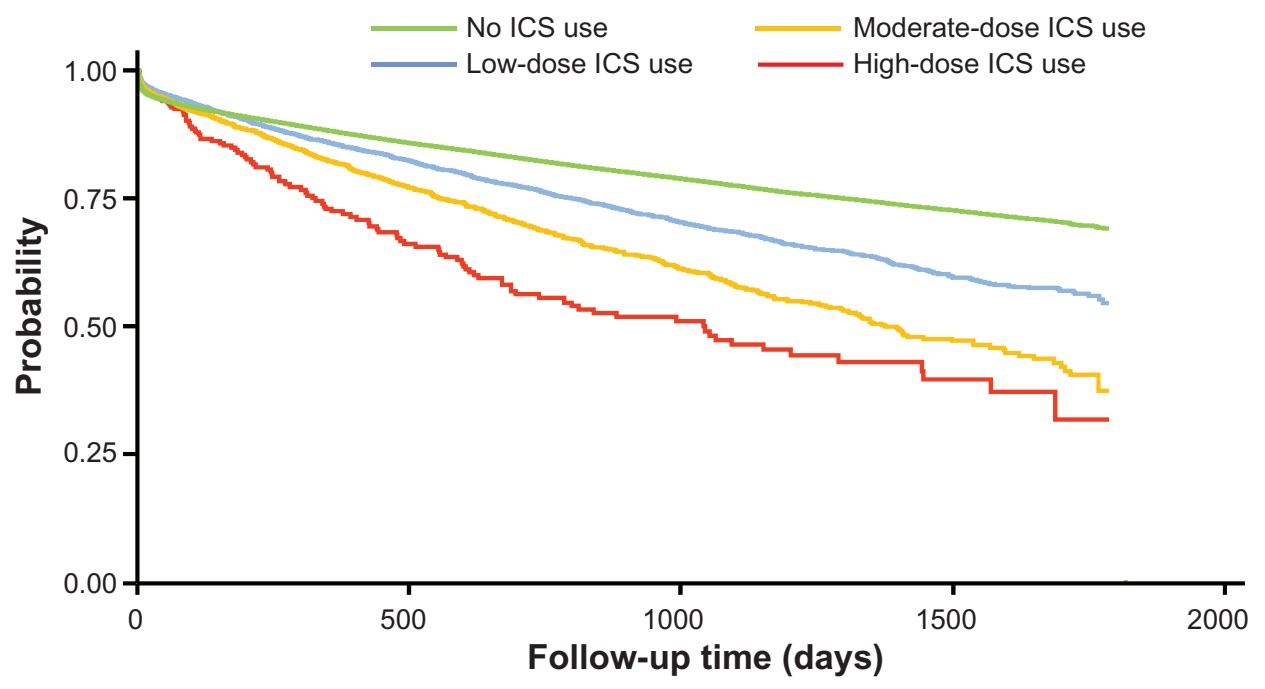

Figure 2 Kaplan-Meier pneumonia-free survival estimates during follow up period by inhaled corticosteroid dose level. Abbreviation: ICS, inhaled corticosteroid. 


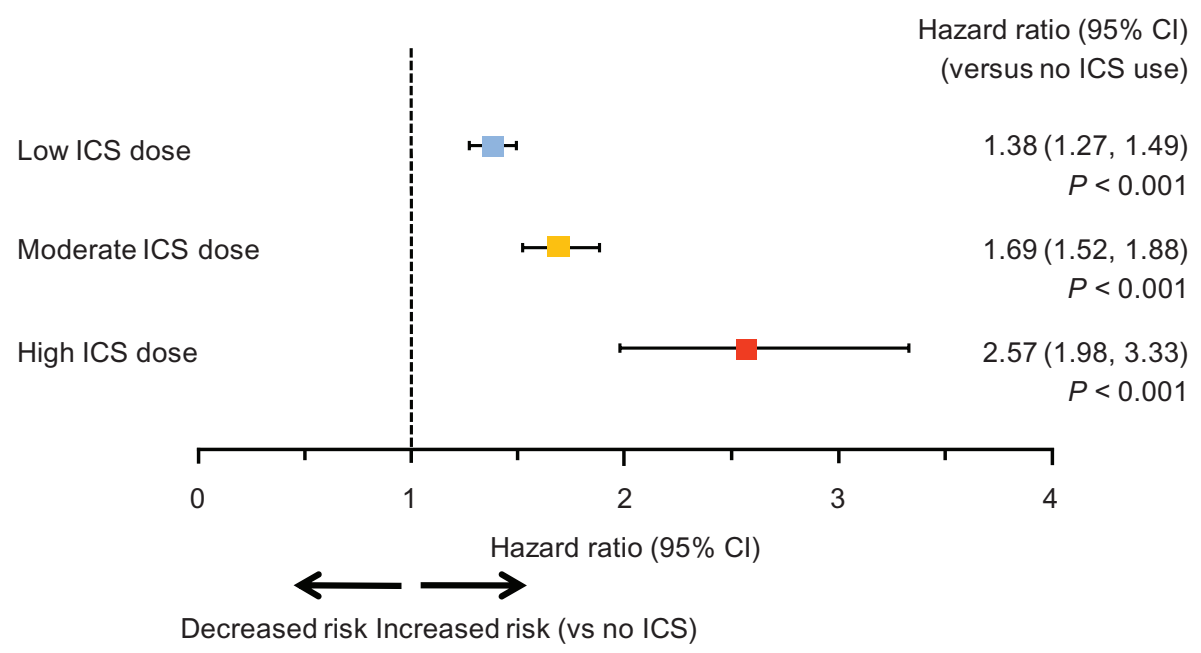

Figure 3 Adjusted hazard ratio for risk of pneumonia according to inhaled corticosteroid dose. Pairwise comparisons between the three ICS dose levels were all significantly different at $P<0.01$. The hazard ratios were from multivariate Cox proportional hazards model, with ICS use and dose level as time-dependent variables.

Abbreviations: $\mathrm{Cl}$, confidence interval; ICS, inhaled corticosteroid.

Cochrane review comparing ICS treatment with placebo reported an increased rate of pneumonia in the ICS group compared with placebo, based on long-term ( $>6$ months) studies that reported pneumonia as an adverse event (odds ratio, 1.56; 95\% CI, 1.30-1.86). ${ }^{24}$ Similar findings of an increased risk of pneumonia with ICS-based treatments compared with placebo or long-acting bronchodilator have been reported in other meta-analyses. ${ }^{25}$ Historically, ICS have been shown to be at their most effective in preventing exacerbations in the subgroup of patients with COPD with repeated exacerbations and more severe airflow limitation. ${ }^{26,27}$ This led to the recommendation for regular ICS therapy as an adjunct in patients experiencing frequent exacerbations and with more severe airflow limitation, with long-acting bronchodilators as frontline therapy for COPD, ${ }^{7,15}$ a recommendation that was endorsed by the authors of the Cochrane review. ${ }^{23}$ Previous reports suggest widespread use of ICS in patients with COPD who do not meet the recommended criteria for their use, ${ }^{1,2,28,29}$ although we are unable to know from the present analysis whether ICS were being used appropriately or not. While it may be argued that ICS are associated with pneumonia as a consequence of their use in patients with frequent exacerbations, $40 \%-50 \%$ of COPD exacerbations are associated with viruses, most commonly rhinovirus, and approximately $22 \%$ are noninfective; of those associated with bacterial infection, pneumonia pathogens are involved in a minority. ${ }^{30,31}$ Respiratory virus infections are associated with more severe and frequent exacerbations. ${ }^{31}$ A UK survey of 9338 patients admitted to hospital for exacerbation of COPD found that only $16 \%$ had radiological changes consistent with pneumonia (and these patients had the worst outcomes). ${ }^{32}$
Our study included patients with a broad range of comorbidities, unlike the typically highly selected group of patients enrolled in clinical drug trials. As noted, we found a significantly independent increase in risk of pneumonia among those with problems of drug or alcohol abuse, a higher Charlson comorbidity score, ${ }^{33}$ congestive heart failure, and diabetes, irrespective of ICS use. The last two conditions are common comorbidities among patients with COPD ${ }^{34-37}$ This suggests the possibility that the incidence of ICS-associated pneumonia among nonselected patients with COPD may be higher than reported in controlled clinical trials. Older age and previous emergency care or hospitalization also contributed independently to pneumonia risk in our study, again regardless of ICS use. The emergency care may have been related to exacerbations of COPD, since all the treatment-related baseline variables associated with increased pneumonia risk were those typically used to manage exacerbations (shortacting "rescue" bronchodilators, antibiotics, and systemic glucocorticoids). A previous exacerbation history has been reported to be a risk factor for pneumonia. ${ }^{17,38}$ To explain this association, it has been postulated that ICS use could lead the patient to delay appropriate therapy for an exacerbation, assuming an infectious etiology, thus enabling intrabronchial sepsis to progress more peripherally. ${ }^{38}$

The mechanism of pneumonia as an adverse effect of ICS use in COPD is not well understood, but may involve a dampening of the host immune response in small airways. Hogg and colleagues examined small airway pathology following lung volume reduction, and the effect of corticosteroids on this pathology, in patients with severe COPD ${ }^{39}$ Corticosteroid treatment was associated with a lowering of the percentage 
of airways containing lymphoid follicles, which indicates a reduction in the adaptive immune response in the peripheral lung. ${ }^{40}$ They postulated that steroid-induced suppression of the host immune response might act in conjunction with extensive mucoid occlusion of the peripheral airways to increase the probability of infection in the lower respiratory tract. In a mouse model, fluticasone was reported to reduce innate pulmonary host defenses and clearance of the bacterial pathogen, causing greater systemic bacterial burden and increased mortality. ${ }^{41}$ There may be difference in immunosuppressive potency between different corticosteroids; based on a meta-analysis of clinical trial data, budesonide was reported to be associated with fewer pneumonia events than fluticasone. ${ }^{42}$ ICS use in COPD patients with pneumonia does not appear to increase mortality risk in patients with COPD, ${ }^{43,44}$ although the data on this issue are limited and factors such as dose, type, and duration of corticosteroid therapy have not been explored. ${ }^{45}$

The nature of claims data, the study design, and the analytical model impose a number of limitations on the present analysis. First, the assumption that the patients with COPD were newly diagnosed was based upon no recorded claims in the 12 months before the COPD diagnosis date. It remains possible that patients may have been diagnosed with COPD while being enrolled in a plan not included in the database. However, we believe it is reasonable to assume that at least one outpatient visit would have occurred during the 12 months before the COPD diagnosis date if this had been the case, making the possibility of preexisting COPD very unlikely. Second, the lack of clinical information in claims databases such as MarketScan ${ }^{\circledR}$ may conceal patient heterogeneity and bias selection, weakening the study's internal validity. Thus, the results of this study may be of limited generalizability beyond the population of patients with COPD residing in the USA who had employer-sponsored health insurance. Third, the database does not provide information on whether pneumonia diagnoses were confirmed radiographically. It is noteworthy that large studies investigating the association of ICS use and the risk of pneumonia in patients with COPD have suggested an increased risk of pneumonia, not radiographically confirmed, based on the strength of the clinical evidence. $^{12,13}$

\section{Conclusion}

Compared with no ICS, we found that ICS use was associated with a significant, potentially dose-related increase in risk of pneumonia in patients with COPD. These results are likely to reflect the real-world conditions of diagnosis, treatment, and treatment-associated side effects among patients with COPD in the US. Our baseline data suggested that older patients with a higher burden of comorbid conditions, and those with a history of hospitalization or emergency visits (for any causes) are at higher risk of pneumonia, and may therefore be particularly vulnerable to pneumonia associated with ICS treatment for COPD. We recommend physicians should use ICS appropriately for those patients with COPD in whom the benefit will outweigh the risk, especially those with previous frequent exacerbations.

\section{Acknowledgments}

This research was funded by Novartis Pharmaceuticals Corporation. The authors received writing assistance from Sarah Filcek and Melanie Stephens (CircleScience); this assistance was funded by Novartis Pharmaceuticals Corporation.

\section{Disclosure}

Dr Tian, Dr Li, Dr Zhang, Dr Arcona and Dr Kahler are employees of Novartis. Dr Yawn has received COPD research funding from Novartis, Boehringer Ingelheim, Pfizer, and GSK within the past 36 months, and received consulting payment from Novartis for the present work. The authors report no other conflicts of interest in this work.

\section{References}

1. Asche CV, Brixner DI, Conoscenti CS, et al. Assessment of physician prescribing for primary care patients with chronic obstructive pulmonary disease (COPD) in a national electronic medical record (EMR) research database. Chest. 2006;130(4):175s [abstract].

2. Bourbeau J, Sebaldt RJ, Day A, et al. Practice patterns in the management of chronic obstructive pulmonary disease in primary practice: the CAGE study. Can Respir J. 2008;15(1):13-19.

3. de Miguel-Díez J, Carrasco-Garrido P, Rejas-Gutierrez J, et al. Inappropriate overuse of inhaled corticosteroids for COPD patients: impact on health costs and health status. Lung. 2011;189(3):199-206.

4. Cazzola M, Segreti A, Bettoncelli G, et al. Change in asthma and COPD prescribing by Italian general practitioners between 2006 and 2008. Prim Care Respir J. 2011;20(3):291-298.

5. Mehuys E, Boussery K, Adriaens E, et al. COPD management in primary care: an observational, community pharmacy-based study. Ann Pharmacother. 2010;44(2):257-266.

6. Smith CJ, Gribbin J, Challen KB, Hubbard RB. The impact of the 2004 NICE guideline and 2003 General Medical Services contract on COPD in primary care in the UK. QJM. 2008;101(2):145-153.

7. Global strategy for diagnosis, management and prevention of chronic obstructive pulmonary disease [homepage on the Internet]. Global Initiative for Chronic Obstructive Lung Disease (GOLD) [updated Dec 2011]. Available from: http://www.goldcopd.org/. Accessed August 20, 2012.

8. Singh S, Loke YK. An overview of the benefits and drawbacks of inhaled corticosteroids in chronic obstructive pulmonary disease. Int J Chron Obstruct Pulmon Dis. 2010;5:189-195.

9. Patel AR, Hurst JR. Extrapulmonary comorbidities in chronic obstructive pulmonary disease: state of the art. Expert Rev Respir Med. 2011;5(5): $647-662$. 
10. Calverley PM, Anderson JA, Celli B, et al. Salmeterol and fluticasone propionate and survival in chronic obstructive pulmonary disease. N Engl J Med. 2007;356(8):775-789.

11. Kardos P, Wencker M, Glaab T, Vogelmeier C. Impact of salmeterol/ fluticasone propionate versus salmeterol on exacerbations in severe chronic obstructive pulmonary disease. Am J Respir Crit Care Med. 2007;175(2):144-149.

12. Wedzicha JA, Calverley PM, Seemungal TA, et al. The prevention of chronic obstructive pulmonary disease exacerbations by salmeterol/ fluticasone propionate or tiotropium bromide. Am J Respir Crit Care Med. 2008;177(1):19-26.

13. Ernst P, Gonzalez AV, Brassard P, Suissa S. Inhaled corticosteroid use in chronic obstructive pulmonary disease and the risk of hospitalization for pneumonia. Am J Respir Crit Care Med. 2007;176(2):162-166.

14. CG101 Chronic obstructive pulmonary disease (update): full guideline [webpage on the Internet]. National Institute for Health and Clinical Excellence [updated May 30, 2012]. Available from: http://guidance. nice.org.uk/CG101/Guidance/pdf/English. Accessed August 20 2012.

15. Qaseem A, Wilt TJ, Weinberger SE, et al. Diagnosis and management of stable chronic obstructive pulmonary disease: a clinical practice guideline update from the American College of Physicians, American College of Chest Physicians, American Thoracic Society, and European Respiratory Society. Ann Intern Med. 2011;155(3):179-191.

16. Colice GL. Pragmatic research and outcomes in asthma and COPD. Pragmatic Obs Res. 2012;3:11-25.

17. Crim C, Calverley PM, Anderson JA, et al. Pneumonia risk in COPD patients receiving inhaled corticosteroids alone or in combination: TORCH study results. Eur Respir J. 2009;34(3):641-647.

18. Walsh LJ, Wong CA, Oborne J, et al. Adverse effects of oral corticosteroids in relation to dose in patients with lung disease. Thorax. 2001;56(4):279-284.

19. Inhaled steroids approximate dose conversions for adults [webpage on the Internet]. Greater Rochester Independent Practice Association (GRIPA). 2005. Available from: http://gripa.org/Documents/Pharmacytidbits/Steroid-Inhaler-Conversion-Chart-12-05-Pharmacy-Tidbit.pdf. Accessed February 1, 2012.

20. Joo MJ, Au DH, Fitzgibbon ML, Lee TA. Inhaled corticosteroids and risk of pneumonia in newly diagnosed COPD. Respir Med. 2010 104(2):246-252.

21. Minas M, Hatzoglou C, Karetsi E, et al. COPD prevalence and the differences between newly and previously diagnosed COPD patients in a spirometry program. Prim Care Respir J. 2010;19(4):363-370.

22. Centers for Disease Control and Prevention (CDC). Chronic obstructive pulmonary disease and associated health-care resource use - North Carolina, 2007 and 2009. MMWR Morb Mortal Wkly Rep. 2012;61(8): 143-146.

23. Spencer S, Karner C, Cates CJ, Evans DJ. Inhaled corticosteroids versus long-acting beta ${ }_{2}$-agonists for chronic obstructive pulmonary disease. Cochrane Database Syst Rev. 2011;12:CD007033.

24. Yang IA, Clarke MS, Sim EH, Fong KM. Inhaled corticosteroids for stable chronic obstructive pulmonary disease. Cochrane Database Syst Rev. 2012;7:CD002991.

25. Singh S, Amin AV, Loke YK. Long-term use of inhaled corticosteroids and the risk of pneumonia in chronic obstructive pulmonary disease: a meta-analysis. Arch Intern Med. 2009;169(3):219-229.

26. Jones PW, Willits LR, Burge PS, Calverley PM; Inhaled Steroids in Obstructive Lung Disease in Europe study investigators. Disease severity and the effect of fluticasone propionate on chronic obstructive pulmonary disease exacerbations. Eur Respir J. 2003;21(1):68-73.

27. Calverley P, Pauwels R, Vestbo J, et al. Combined salmeterol and fluticasone in the treatment of chronic obstructive pulmonary disease: a randomised controlled trial. Lancet. 2003;361(9356):449-456. Erratum in: Lancet. 2003;361(9369):1660.
28. Yawn B, Kleerup E, Zhang J, Kianifard F, Williams J. Inhaled corticosteroid use and GOLD severity stage among patients with chronic obstructive pulmonary disease in different regions. Am J Respir Crit Care Med. 2012;185:A2944. [abstract].

29. Chen S, Plauschinat CA, Wu N, Fraser K, Boulanger L. Economic impact of using inhaled corticosteroids without prior exacerbation among elderly patients with chronic obstructive pulmonary disorder. J Med Econ. 2011;14(4):458-462.

30. Papi A, Bellettato CM, Braccioni F, et al. Infections and airway inflammation in chronic obstructive pulmonary disease severe exacerbations. Am J Respir Crit Care Med. 2006;173(10):1114-1121.

31. Seemungal T, Harper-Owen R, Bhowmik A, et al. Respiratory viruses, symptoms, and inflammatory markers in acute exacerbations and stable chronic obstructive pulmonary disease. Am J Respir Crit Care Med. 2001;164(9):1618-1623.

32. Myint PK, Lowe D, Stone RA, Buckingham RJ, Roberts CM. UK National COPD Resources and Outcomes Project 2008: patients with chronic obstructive pulmonary disease exacerbations who present with radiological pneumonia have worse outcome compared to those with non-pneumonic chronic obstructive pulmonary disease exacerbations. Respiration. 2011;82(4):320-327.

33. Charlson M, Szatrowski TP, Peterson J, Gold J. Validation of a combined comorbidity index. J Clin Epi. 1994;47:1246-1261.

34. Finkelstein J, Cha E, Scharf SM. Chronic obstructive pulmonary disease as an independent risk factor for cardiovascular morbidity. Int J Chron Obstruct Pulmon Dis. 2009;4:337-349.

35. Dai S, Walsh P, Wielgosz A, Gurevich Y, Bancej C, Morrison H. Comorbidities and mortality associated with hospitalized heart failure in Canada. Can J Cardiol. 2012;28(1):74-79.

36. Mannino DM, Thorn D, Swensen A, Holguin F. Prevalence and outcomes of diabetes, hypertension and cardiovascular disease in COPD. Eur Respir J. 2008;32(4):962-969.

37. Rana JS, Mittleman MA, Sheikh J, et al. Chronic obstructive pulmonary disease, asthma, and risk of type 2 diabetes in women. Diabetes Care. 2004;27(10):2478-2484.

38. Calverley PM, Stockley RA, Seemungal TA, et al. Reported pneumonia in patients with COPD: findings from the INSPIRE study. Chest. 2011; 139(3):505-512.

39. Hogg JC, Chu FS, Tan WC, et al. Survival after lung volume reduction in chronic obstructive pulmonary disease: insights from small airway pathology. Am J Respir Crit Care Med. 2007;176(5):454-459.

40. Hogg JC, Chu F, Utokaparch S, et al. The nature of small-airway obstruction in chronic obstructive pulmonary disease. $N$ Engl J Med. 2004;350(26):2645-2653.

41. Patterson CM, Morrison RL, D’Souza A, Teng XS, Happel KI. Inhaled fluticasone propionate impairs pulmonary clearance of Klebsiella pneumoniae in mice. Respir Res. 2012;13(1):40.

42. Halpin DM, Gray J, Edwards SJ, Morais J, Singh D. Budesonide/ formoterol vs salmeterol/fluticasone in COPD: a systematic review and adjusted indirect comparison of pneumonia in randomised controlled trials. Int J Clin Pract. 2011;65(7):764-774.

43. Singanayagam A, Chalmers JD, Akram AR, Hill AT. Impact of inhaled corticosteroid use on outcome in COPD patients admitted with pneumonia. Eur Respir J. 2011;38(1):36-41.

44. Chen D, Restrepo MI, Fine MJ, et al. Observational study of inhaled corticosteroids on outcomes for COPD patients with pneumonia. Am J Respir Crit Care Med. 2011;184(3):312-316.

45. Restrepo MI, Mortensen EM, Anzueto A. Are COPD patients with pneumonia who are taking inhaled corticosteroids at higher risk of dying? Eur Respir J. 2011;38(1):1-3. 


\section{Supplementary table}

Table SI Multivariate Cox proportional hazard model results for risk of pneumonia

\begin{tabular}{|c|c|c|c|c|c|}
\hline Variable & Hazard ratio & SE & $P>z$ & Lower $95 \% \mathrm{Cl}$ & Upper $95 \% \mathrm{Cl}$ \\
\hline ICS low dose (reference no ICS) & 1.38 & 0.06 & 0.000 & 1.27 & 1.49 \\
\hline ICS moderate dose (reference no ICS) & 1.69 & 0.09 & 0.000 & 1.52 & 1.88 \\
\hline ICS high dose (reference no ICS) & 2.57 & 0.34 & 0.000 & 1.98 & 3.33 \\
\hline Charlson comorbidity score & 1.07 & 0.00 & 0.000 & 1.06 & 1.08 \\
\hline Hospitalization (yes vs no) & 1.16 & 0.02 & 0.000 & 1.12 & 1.20 \\
\hline ER (yes vs no) & 1.25 & 0.02 & 0.000 & 1.21 & 1.28 \\
\hline Age & 1.03 & 0.00 & 0.000 & 1.03 & 1.03 \\
\hline Female sex & 0.97 & 0.01 & 0.010 & 0.95 & 0.99 \\
\hline Non-FFS health plan (vs FFS) & 0.94 & 0.02 & 0.008 & 0.90 & 0.99 \\
\hline Region North Central (vs Northeast) & 1.05 & 0.02 & 0.018 & 1.01 & 1.09 \\
\hline Region South (vs Northeast) & 1.07 & 0.02 & 0.003 & 1.02 & I.II \\
\hline Region West (vs Northeast) & 0.96 & 0.02 & 0.061 & 0.91 & 1.00 \\
\hline Year 2007 (vs 2006) & 1.02 & 0.02 & 0.120 & 0.99 & 1.06 \\
\hline Year 2008 (vs 2006) & 1.01 & 0.02 & 0.466 & 0.98 & 1.05 \\
\hline Year 2009 (vs 2006) & 1.02 & 0.02 & 0.265 & 0.98 & 1.06 \\
\hline Year 2010 (vs 2006) & 1.09 & 0.03 & 0.001 & 1.03 & 1.14 \\
\hline Liver disease & 1.05 & 0.05 & 0.318 & 0.95 & 1.15 \\
\hline Peripheral vascular disorder & 1.01 & 0.02 & 0.520 & 0.98 & 1.05 \\
\hline Valvular disease & 0.97 & 0.02 & 0.090 & 0.93 & 1.01 \\
\hline Congestive heart failure & 1.25 & 0.02 & 0.000 & 1.21 & 1.30 \\
\hline Drug abuse & 1.55 & 0.13 & 0.000 & 1.32 & 1.82 \\
\hline Alcohol abuse & 1.27 & 0.08 & 0.000 & 1.12 & 1.43 \\
\hline Hypertension & 0.94 & 0.01 & 0.000 & 0.91 & 0.96 \\
\hline Pulmonary circulation disorder & 0.92 & 0.04 & 0.046 & 0.86 & 1.00 \\
\hline Diabetes & 1.07 & 0.02 & 0.000 & 1.04 & 1.10 \\
\hline Short-acting $\beta_{2}$-agonists & 1.16 & 0.03 & 0.000 & 1.10 & 1.21 \\
\hline Long-acting $\beta_{2}$-agonists & 1.05 & 0.10 & 0.646 & 0.86 & 1.26 \\
\hline Short-acting anticholinergics & 1.14 & 0.05 & 0.005 & 1.04 & 1.26 \\
\hline Long-acting anticholinergics & 0.81 & 0.04 & 0.000 & 0.74 & 0.88 \\
\hline Methylxanthines & 0.94 & 0.09 & 0.549 & 0.78 & 1.14 \\
\hline Systemic glucocorticoids & 1.30 & 0.03 & 0.000 & 1.26 & 1.36 \\
\hline Mast-cell stabilizers & 0.83 & 0.31 & 0.612 & 0.39 & 1.73 \\
\hline Leukotriene modifiers & 0.96 & 0.05 & 0.395 & 0.88 & 1.05 \\
\hline Antibiotics & 1.09 & 0.01 & 0.000 & 1.07 & 1.12 \\
\hline
\end{tabular}

Abbreviations: $\mathrm{Cl}$, confidence interval; ER, emergency room; ICS, inhaled corticosteroids; FFS, fee for service; HR, hazard ratio.

\section{Publish your work in this journal}

The International Journal of COPD is an international, peer-reviewed journal of therapeutics and pharmacology focusing on concise rapid reporting of clinical studies and reviews in COPD. Special focus is given to the pathophysiological processes underlying the disease, intervention programs, patient focused education, and self management protocols.

\section{Dovepress}

This journal is indexed on PubMed Central, MedLine and CAS. The manuscript management system is completely online and includes a very quick and fair peer-review system, which is all easy to use. Visit $\mathrm{http}: / / \mathrm{www}$.dovepress.com/testimonials.php to read real quotes from published authors. 